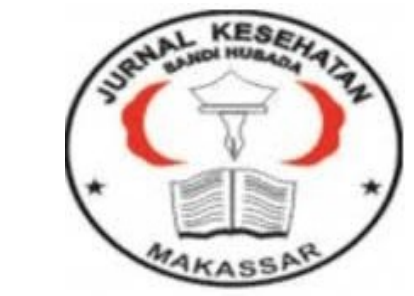

Jurnal Ilmiah Kesehatan Sandi Husada

hhttps://akper-sandikarsa.e-journal.id/JIKSH

Vol 11, No, 1, Juni 2020, pp;461-466

p-ISSN: 2354-6093 dan e-ISSN: 2654-4563

DOI: $10.35816 /$ jiskh.v10i2.324

\title{
Studi Kasus Pasien dengan Diare Rumah Sakit di Kota Makassar
}

ARTIKEL PENELITIAN

Case Study of Patients with Diare Hospital in Makassar City

Darmi Arda', Hartaty ${ }^{2}$, Hasriani ${ }^{3}$

12 Keperawatan, Politeknik Sandi Karsa Makassar

\section{Artikel info \\ Artikel history:}

Received; 20 April 2020

Revised: 27 Mei 2020

Accepted; 28 Mei 2020

\begin{abstract}
.
Diarrhea is the most common cause of death in infants and toddlers. Diarrhea causes poor nutritional status and poor nutritional status and causes growth failure, even permanent weight loss caused by fluid loss and dehydration. The perceived problem is defecation with a soft or liquid consistency, it can even be in the form of water only and the frequency is more often usually three times or more in one day. This case study aims to look at nursing care provided to clients suffering from diarrhea. The research design uses case studies, which aim to describe the nursing care that is carried out. The number of samples 2 people were observed for 3 days in the hospital. The results of observations in the case of patients 1 age 2.5 years with complaints of diarrhea, vomiting and heat with a temperature of $38.3^{\circ} \mathrm{C}$. In the case of 2 patients aged 3 years with complaints of diarrhea and vomiting. Nursing diagnoses in both cases namely diarrhea are associated with intestinal inflammation. Planned interventions are managing diarrhea, monitoring vital signs, managing drug therapy. The implication of this research is to optimize the management of diarrhea in nursing care in Toodler children with acute liquid diarrhea with mild to moderate dehydration.
\end{abstract}

Abstrak.

Diare merupakan penyebab kematian terbanyak pada bayi dan balita. Diare menyebabkan status gizi buruk dan status gizi buruk serta menyebabkan kegagalan dalam pertumbuhan, bahkan kehilangan berat badan yang menetap yang disebabkan oleh kehilangan cairan dan dehidrasi. Masalah yang dirasakan yaitu buang air besar dengan konsistensi lembek atau cair, bahkan dapat berupa air saja dan frekuensinya lebih sering biasanya tiga kali atau lebih dalam satu hari. Studi kasus ini bertujuan untuk melihat asuhan keperawatan yang diberikan pada klien yang menderita Diare. Desain penelitian menggunakan studi kasus, yang bertujuan untuk menggambarkan asuhan keperawatan yang dilaksanakan. Jumlah sampel 2 orang yang observasi selama 3 hari di Rumah sakit. Hasil observasi pada kasus pasien 1 usia 2,5 tahun dengan keluhan diare, muntah dan panas dengan suhu $38,3^{\circ} \mathrm{C}$. Pada kasus pasien 2 usia 3 tahun dengan keluhan diare dan muntah. Diagnosa keperawatan dari kedua kasus yaitu diare berhubungan dengan inflamasi usus. Intervensi yang 
direncanakan yaitu memanagement diare, memonitor tanda tanda vital, kelola terapi obat. Impikasi dari penelitian dari penelitian ini adalah optimalisasi manajemen diare dalam asuhan keperawatan pada anak usia Toodler dengan diare cair akut dengan dehidrasi ringan sampai sedang.

\author{
Keywords: \\ Diare; \\ Kekurangan Nutrisi, \\ Dehidrasi; \\ Asietas;
}

Corsponden author:

Email: darmiarda@gmail.com

artikel dengan akses terbuka dibawah lisensi BCC BY NC ND-4.0

\section{Pendahuluan}

Penyakit diare masih merupakan masalah kesehatan masyarakat di negara berkembang seperti di Indonesia, karena morbiditas dan mortalitas-nya yang masih tinggi. Survei morbiditas yang dilakukan oleh Subdit Diare, Departemen Kesehatan dari tahun $2000 \mathrm{~s} / \mathrm{d}$ 2010 terlihat kecenderungan insidens naik. Pada tahun 2000 IR penyakit Diare 301/ 1000 penduduk, tahun 2003 naik menjadi $374 / 1000$ penduduk, tahun 2006 naik menjadi 423 /1000 penduduk dan tahun 2010 menjadi 411/1000 penduduk. Kejadian Luar Biasa (KLB) diare juga masih sering terjadi, dengan CFR yang masih tinggi. Pada tahun 2008 terjadi KLB di 69 Kecamatan dengan jumlah kasus 8133 orang, kematian 239 orang (CFR 2,94\%). Tahun 2009 terjadi KLB di 24 Kecamatan dengan jumlah kasus 5.756 orang, dengan kematian 100 orang (CFR 1,74\%), sedangkan tahun 2010 terjadi KLB diare di 33 kecamatan dengan jumlah penderita 4204 dengan kematian 73 orang (CFR 1,74 \%.)(Kemenkes RI, 2011)

Prevalensi diare dalam Riskesdas 2007 diukur dengan menanyakan apakah responden pernah didiagnosis diare oleh tenaga kesehatan dalam satu bulan terakhir. Responden yang menyatakan tidak pernah, ditanya apakah dalam satu bulan tersebut pernah menderita buang air besar $>3$ kali sehari dengan kotoran lembek/cair. Responden yang menderita diare ditanya apakah minum oralit atau cairan gula garam. Prevalensi diare klinis adalah 9,0\% (rentang: 4,2\% - 18,9\%), tertinggi di Provinsi NAD (18,9\%) dan terendah di DI Yogyakarta (4,2\%). Beberapa provinsi mempunyai prevalensi diare klinis $>9 \%$ (NAD, Sumatera Barat, Riau, Jawa Barat, Jawa Tengah,Banten, Nusa Tenggara Barat, Nusa Tengara Timur, Kalimantan Selatan, Sulawesi Tengah, Sulawesi Tenggara, Gorontalo, Papua Barat dan Papua) (Kementerian Kesehatan Republik Indonesia, 2008)

Diare adalah kehilangan cairan dan elektrolit secara berlebihan yang terjadi karena frekwensi satu kali atau lebih buang air besar dengan bentuk tinja yang encer atau cair (Suriadi, 2001). Diare adalah peningkatan keenceran dan frekuensi feses. Diare mungkin dalam volume besar atau sedikit dan dapat disertai atau tanpa darah. Diare dapat terjadi akibat adanya zat terlarut yang tidak dapat diserap di dalam feses, yang di sebut diare osmotik, atau karena iritasi saluran cerna. Penyebab tersering diare dalam volume besar akibat iritasi adalah infeksi atau bakteri di usus halus distal atau usus besar (Corwin, 2001).

Menurut hasil penelitian (Seweng, etal, 2010) bahwa ada perbedaan dalam tingkat kejadian diare, di mana tingkat kejadian yang lebih tinggi diamati di pusat-pusat kesehatan tanpa program klinik sanitasi dibandingkan dengan mereka yang memiliki program klinik sanitasi. Hal ini dikonfirmasi oleh temuan bahwa dari 369 responden yang diteliti, 145 (39,3\%) menderita diare, 41 (19,3\%) berada di area puskesmas dengan klinik sanitasi, dan $104(66,2 \%)$ berlokasi di area puskesmas tanpa program. 
Bahwa ada perbedaan yang signifikan dalam sanitasi dasar, di mana persentase kepemilikan infrastruktur yang lebih tinggi diamati di pusat-pusat kesehatan dengan program dibandingkan dengan mereka yang tidak memiliki program klinik sanitasi. didapatkan ada hubungan antara penyediaan air bersih dengan kejadian diare, ada hubungan antara pengolahan sampah rumah tangga dengan kejadian diare, terdapat hubungan antara penggunaan jamban dengan kejadian diare dan terdapat hubungan antara penggunaan SPAL dengan kejadiaan diare. Terdapat hubungan antara penyediaan air bersih, pengelolaan sampah rumah tangga, penggunaan jamban keluarga,dan penggunaan SPAL dengan kejadian diare pada lanjut usia di Kelurahan Barombong Kecamatan Tamalate Kota Makassar (Suprapto, 2017).

Berdasarkan data di atas diare menempati urutan kelima menyumbang kematian pada anak di seluruh dunia. Penyebab utama kematian diare adalah dehidrasi akibat kehilangan cairan dan elektrolit melalui tinja. Penyebab lainnya adalah disentri, kurang gizi, dan infeksi. Golongan umur yang paling menderita akibat diare adalah anak - anak karena daya tahan tubuhnya masih lemah. Berdasarkan alasan tersebut peneliti tertarik melakukan studi kasus tentang penyakit Diare pada anak di Rumah Sakit Ibnu Sina Makassar.

\section{Metode}

Desain penelitian menggunakan studi kasus secara deskriptif yang bertujuan untuk menggambarkan asuhan keperawatan yang dilaksanakan. Jumlah sampel 2 orang yang observasi, dimana dalam studi kasus ini akan menjelaskan tentang kasus yang dialami oleh pasien dengan diare, subyek studi kasus adalah anak yang mengalami diare. Metode pengumpulan data yang digunakan oleh peneliti pada studi kasus ini adalah dengan cara wawancara, observasi dan pemeriksaan fisik penyajian data dibuat oleh peneliti dalam bentuk teks naratif, dimana data dalam studi kasus dibuat dalam suatu rangkaian kalimat yang menceritakan suatu rangkaian kejadian. Penyajian data dapat disertai dengan ungkapan secara verbal dari subyek studi kasus yang merupakan data pendukungnya.

\section{Hasil Dan Pembahasan}

\section{Pengkajian}

Hasil pengkajian yang dilakukan di dapatkan data yang mengacuh pada masalah yang di hadapai An"R" yaitu BAB 5 x sehari, dengan konsistensi encer, berampas, anak malas makan, anak malas minum, berat badan menurun, suhu badan $37,4^{\circ} \mathrm{C}$, mata cekung, turgor kulit kurang elastis, keadaan umum lemah, bibi kering, membran mukosa kering, anus kemerahan, tingkat dehidrasi dengan skor 5: sedang, Berat badan $10 \mathrm{~kg}$. Sedangkan pengkajian yang ada pada teori tapi tidak ada pada kasus adalah adanya distensi abdomen, ubun-ubun besar.

Menurut (Sugiyarti, 2019) hasil observasi pada kasus pasien 1 usia 2,5 tahun dengan keluhan diare, muntah dan panas dengan suhu 38,3ํㅡ. Pada kasus pasien 2 usia 3 tahun dengan keluhan diare dan muntah. Diagnosa keperawatan dari kedua kasus yaitu diare berhubungan dengan inflamasi usus. Intervensi yang direncanakan yaitu memanagement diare, memonitor tanda tanda vital, kelola terapi obat. Impikasi dari penelitian dari penelitian ini adalah optimalisasi manajemen diare dalam asuhan keperawatan pada anak 
usia Toodler dengan diare cair akut dengan dehidrasi ringan sampai sedang

\section{Diagnosa}

Berdasarkan pengkajian diagnose keperawatan yang ditemukan; kekurangam volume cairan berhubungan dengan asupan cairan yang tidak adekuat, kekurangan nutrisi kurang dari kebutuhan tubuh berhubungan dengan penurunan intake makanan, anoreksia Ansietas berhubungan dengan kurangnya informasi tentang penyakit anaknya.

Menurut (Sodikin, 2011) bahwa diagnosa keperawatan yang sering muncul pada Diare kekurangan volume cairan berhubungan dengan kehilangan cairan yang berlebihan dari traktus gastrointestinal dalam feses atau muntahan (emesis). Perubahan nutrisi kurang dari kebutuhan tubuh berhubungan dengan kehilangan cairan akibat diare, dan asupan cairan yang tidak adekuat. Resiko menularkan infeksi berhubungan dengan mikroorganisme yang menginvasi traktus gastroentestinal. Kerusakan integritas kulit berhubungan dengan iritasi karena defekasi yang sering dan feses yang cair. Ansietas (takut) berhubungan dengan perpisahan dengan orang tua, lingkungan tidak kenal, prosedur yang menimbulkan stress.

(Fatonah, 2012) berpendapat bahwa setelah dilakukan asuhan keperawatan selama 3x24 jam didapatkan hasil nutrisi pasien adekuati, volume cairan terpenuhi, dan tidak terjadi infeksi. Dalam melakuakan asuhan keperawatan pada pasien diperlukan kerjasama baik dari tim kesehatan, pasien, maupun keluarga karena sangat diperlukan untuk keberhasilan asuhan keperawatan pada pasien. Komunikasi terapeutik dapat mendorong pasien lebih kooperatif.

\section{Perencanaan}

Pada masalah keperawatan kekurangan volume cairan dan elektrolit perencanan yang dilakukan; kaji derajat dehidrasi, kaji tanda tanda vital dan keadaan umum pasien, observasi kelembapan kulit, berikan dan pantau cairan infus sesuai program.

Kekurangan nutrisi kurang intervensi yang dilakukan Observasi pola pemenuhan nutrisi pasien, Anjutkan ibu pasien untuk menberikan makanan tapi sering, anjurkan ibu pasien untuk menyajikan makanan dalam kedaan hangat, timbang BB pasien. Berdasarkan data intervensi di atas data yang ada di teori tapi tidak ditemukan di kasus adalah pemberian ASI.

Ansietas yang dilakukan Kaji tingkat kecemasan ibu pasien, berikan kesempatan ibu pasien untuk mengungkapkan perasaannya, berikan support dan motivasi kepada ibu pasien. Berdasarkan data intervensi di atas tidak ada kesenjangan antara teori dan kasus karena di teori kecemasan pada anak sedangkan di kasus kecemasan orang tua pasien Berdasarkan data intervensi di atas data yang ada diteori tapi tidak di temukan di kasus adalah berikan oralit secara bergantian dengan cairan rendah natrium seperti ASI atau susu formula, pertahankan asupan cairan (urine, feses dan cairan) pantau berat jenis urine setiap 8 jam. Berdasarkan data intervensi tidak ada kesenjangan antara teori dan kasus. 


\section{Implementasi}

Pelaksanaan adalah pengetahuan dan pewujudan dari rencana perawatan yang dibuat, yang meliputi tindakan-tindakan sesuai dengan, dapat dilaksanakan oleh perawat, pasien sendiri, atau dilakukan dengan bekerja sama dengan anggota tim kesehatan lain.

Kekurangam volume cairan; pada waktu menulis pengkajian di dapatkan data dimana pada hari pertama pengkajian di dapatkan pasien BAB dengan konsistensi encer keadaan umum lemah, mata cekung bibir kering membran mukosa kering dan pada hari kedua pengkajian penulis masih mendapatkan data dari pasien bahwa kekurangan volume cairan dan elektrolit belum terpenuhi penulis menganjurkan untuk banyak minum.

Kekurangan nutrisi kurang dari kebutuhan tubuh; pada waktu penulis melakukan pengkajian di dapatkan data di mana pasien malas makan selama sakit, porsi makan tidak dihabiskan adapun tindakan yang di lakukan penulis saat pengkajian yaitu pemberian diet tapi sering, dan disajikan dalam keadaan hangat, timbang berat badan.

Ansietas; pada waktu penulis melakukan pengkajian di dapatkan data di mana ibu pasien cemas terhadap kondisi anaknya, ingin anaknya segera sembuh, ibu pasien selalu menanyakan keadaan anaknya. Adapun tindakan yang di berikan kepada orang tua pasien adalah memberikan penjelasan terhadap kondisi anaknya, memberikan motivasi dan support agar tidak terlalu cemas terhadap kondisi anaknya.

Adapun tindakan keperawatan yang telah di lakukan untuk mengatasi diagnosa diare adalah mengobservasi turgor kulit secara rutin, mengkaji pola defekasi pasien konsistensi dan warna feses, mengkaji peristaltik usus, mengkaji tanda-tanda dehidrasi, mengkaji tanda-tanda dehidrasi, menganjurkan minum banyak dan jaga kebersihan lingkungan (Rahayu, 2016).

\section{Evaluasi}

Evaluasi adalah penilaian pencapaian tujuan serta pengkajian ulang rencana keperawatan. Tahap evaluasi merupakan kunci keberhasilan dalam menggunakan proses keperawatan. Hal-hal yang perlu di evaluasi adalah keakuratan, kelengkapan dan kualitas data, teratasi atau tidaknya masalah pasien, pencapaian tujuan serta ketetapan intervensi keperawatan. Berdasarkan tindakan keperawatan maka dapat disimpulkan bahwa semua masalah teratasi sehingga pertahankan intervensi.

\section{Simpulan Dan Saran}

Berdasarkan hasil studi kasus pasien anak dengan diare masalah keperawatan yang sering timbul adalah kekurangan volume cairan, perubahan nutrisi kurang, dan asupan cairan yang tidak adekuat, resiko menularnya infeksi dan kerusakan integritas kulit berhubungan dengan iritasi karena defekasi yang sering dan feses yang cair, ansietas (takut) berhubungan dengan perpisahan dengan orang tua ,lingkungan yang tidak dikenal, prosedur yang menimbulkan stress. Dari kelima masalah, tiga diantaranya ditemukan pada pasien yaitu kekurangan volume cairan, kekurangan nutrisi kurang dari kebutuhan tubuh, ansietas.

Rumah sakit tentunya dapat meningkatkan mutu asuhan keperawatan pasien terutama 
untuk mencapai derajat kesehatan masyarakat yang optimal dan menganjurkan kepada pasien dan keluarga untuk mengikuti penyuluhan agar pasien dapat mengetahui tentang Diare yang terjadi.

\section{Daftar Rujukan}

Corwin, E. J. (2001). Buku Saku Patofisiologi. Alih Bahasa: Brahm U.Pendit. Editor (Endah P, Ed.). Jakarta: EGC.

Fatonah, M. S. (2012). Asuhan Keperawatan Pada An. R Dengan Gangguan Sistem Pencernaan: Gastroenteritis Di Ruang Mina RS PKU Muhammadiyah Surakarta. Universitas Muhammadiyah Surakrta.

Kemenkes RI. (2011). Situasi diare di Indonesia. In Jurnal Buletin Jendela Data \& Informasi Kesehatan (Vol. 2, pp. 1-44).

Kementerian Kesehatan Republik Indonesia. (2008). Laporan Nasional Riskesdas 2007. In Badan Penelitian dan Pengembangan Kesehatan Departemen Kesehatan, Republik Indonesia Desember 2008 (pp. 1-384). https://doi.org/1 December 2013

Rahayu, E. M. (2016). Asuhan Keperawatan Pada Tn. S Dengan Gastroenteritis Akut Di Ruang Gladiol Atas Rumah Sakit Umum Daerah Sukoharjo. STIKES Muhammadiyah Klaten.

Seweng, A., Ishak, H., \& Syarifuddin, S. (2010). Hubungan Pelaksanaan Klinik Sanitasi dengan Kejadian Diare di Kabupaten Takalar. Media Kesehatan Masyarakat Indonesia Universitas Hasanuddin, 6(2), 27367.

Sodikin. (2011). Asuhan Keperawatan Anak: Gangguan Sistem Gastrointestinal dan Hepatobilier. Jakarta: Salemba Medika.

SUGIYARTI, E. (2019). Asuhan Keperawatan Pada Anak Usia Toddler Dengan Diare Cair Akut Dehidrasi Ringan Sampai Sedang Di Rsud Pandan Arang Boyolali. STIKES Muhammadiyah Klaten.

Suprapto, N. (2017). Hubungan Sanitasi Lingkungan Dengan Kejadian Diare Pada Lanjut Usia Di Kelurahan Barombong Kecamatan Tamalate Kota Makassar. Jurnal Ilmiah Kesehatan Sandi Husada, 5(2), 47-64.

Suriadi, R. Y. (2001). Asuhan Keperawatan Pada Penyakit Dalam. Edisi 1. Jakarta: Agung Setia. 